\title{
Adaptation of Translational Machinery in Malaria Parasites to Accommodate Translation of Poly-Adenosine Stretches Throughout Its Life Cycle
}

\author{
Jessey Erath, Sergej Djuranovic* and Slavica Pavlovic Djuranovic* \\ Department of Cell Biology and Physiology, Washington University School of Medicine, St. Louis, MO, United States
}

\section{OPEN ACCESS}

Edited by: Rhoel Dinglasan,

University of Florida, United States

Reviewed by:

Scott E. Lindner,

Pennsylvania State University (PSU),

United States

Vasant Muralidharan,

University of Georgia, United States

*Correspondence:

Sergej Djuranovic sergej.djuranovic@wustl.edu

Slavica Pavlovic Djuranovic spavlov@wustl.edu

Specialty section: This article was submitted to

Infectious Diseases,

a section of the journa

Frontiers in Microbiology

Received: 26 September 2019 Accepted: 21 November 2019

Published: 06 December 2019

Citation:

Erath J, Djuranovic $S$ and Djuranovic SP (2019) Adaptation of Translational Machinery in Malaria

Parasites to Accommodate

Translation of Poly-Adenosine Stretches Throughout Its Life Cycle.

Front. Microbiol. 10:2823.

doi: 10.3389/fmicb.2019.02823
Malaria is caused by unicellular apicomplexan parasites of the genus Plasmodium, which includes the major human parasite Plasmodium falciparum. The complex cycle of the malaria parasite in both mosquito and human hosts has been studied extensively. There is tight control of gene expression in each developmental stage, and at every level of gene synthesis: from RNA transcription, to its subsequent translation, and finally post-translational modifications of the resulting protein. Whole-genome sequencing of $P$. falciparum has laid the foundation for significant biological advances by revealing surprising genomic information. The $P$. falciparum genome is extremely AT-rich ( $80 \%)$, with a substantial portion of genes encoding intragenic polyadenosine (polyA) tracks being expressed throughout the entire parasite life cycle. In most eukaryotes, intragenic polyA runs act as negative regulators of gene expression. Recent studies have shown that translation of mRNAs containing 12 or more consecutive adenosines results in ribosomal stalling and frameshifting; activating mRNA surveillance mechanisms. In contrast, $P$. falciparum translational machinery can efficiently and accurately translate polyA tracks without activating mRNA surveillance pathways. This unique feature of $P$. falciparum raises interesting questions: (1) How is $P$. falciparum able to efficiently and correctly translate polyA track transcripts, and (2) What are the specifics of the translational machinery and mRNA surveillance mechanisms that separate $P$. falciparum from other organisms? In this review, we analyze possible evolutionary shifts in $P$. falciparum protein synthesis machinery that allow efficient translation of an AU richtranscriptome. We focus on physiological and structural differences of $P$. falciparum stage specific ribosomes, ribosome-associated proteins, and changes in mRNA surveillance mechanisms throughout the complete parasite life cycle, with an emphasis on the mosquito and liver stages.

Keywords: plasmodium, ribosomes, mRNA surveillance, AT rich genome, mRNA translation 


\section{INTRODUCTION}

Plasmodium spp. has been in existence long before humans were on Earth, with an estimated origin of malaria-causing parasites appearing around 165 million years ago. Consequently, mosquitos and malaria had millions of years to co-evolve before either ever interacted with humans (Winegard, 2019). The infection of humans occurred evolutionarily recently, and probably with multiple Plasmodium parasite species. $P$. falciparum and $P$. vivax established themselves as a major malaria causing species. $P$. falciparum a most virulent agent in human malaria began speciation around 50,000 years ago followed by the population bottleneck around 5000 years ago but higher level of genetic diversity suggests that $P$. vivax is older (Loy et al., 2018; Otto et al., 2018). P. malariae, P. ovale, and rare cases of $P$. knowlesi were also reported in human hosts. From the mid-19th century onward, malaria reached its global limits and exacted immensely high numbers in sickness and death. While increased malaria prevention and control treatments have reduced the health burden of malaria, there are still 219 million cases of infection per year resulting in a 435,000 deaths (World Health Organization [WHO], 2018). The complex cycle of the malaria parasite in both mosquito and human hosts has been studied extensively (Figure 1). In each of these life cycle stages, gene expression is tightly controlled (Le Roch et al., 2004; Shock et al., 2007; Hughes et al., 2010; Sorber et al., 2011; Bunnik and Le Roch, 2013; Caro et al., 2014; Vembar et al., 2016a; Lu et al., 2017).

It took years of laborious efforts to sequence $P$. falciparum genome (Kooij et al., 2006). Sequences of single or multiple chromosomes as well as complete genome were reported over the course of 4 years (Gardner et al., 1998, 2002a,b; Bowman et al., 1999; Hall et al., 2002; Hyman et al., 2002). The high AT-content of the genome made gap closure in sequences extremely difficult. However, long-read, single molecule, realtime sequencing allowed for complete telomere-to-telomere de novo assembly of the $P$. falciparum genome thereby overcoming the problems associated with next generation sequencing of ATrich genomes (Vembar et al., 2016b). The consequence of ATrichness is the presence of extended tracts of As, Ts, and TAs in introns and intergenic regions (Glöckner, 2000; Szafranski et al., 2005) as well as unusually high number of genes containing coding polyadenosine (polyA) repeats compared to the other species (Habich, 2016; Djuranovic et al., 2018). Repetitions of 12 or more adenosine nucleotides in gene coding sequences, so-called polyA tracks, were recently found to act as negative gene regulation motifs at the level of mRNA translation in all tested organisms (Arthur et al., 2015; Koutmou et al., 2015). Consequently, polyA tracks have been evolutionarily preserved in a select set of genes, but are generally selected against in overall gene coding sequences (Arthur et al., 2015).

Recent analysis of 250 eukaryotic genomes found a median of $2 \%$ of transcripts with polyA tracks (Habich, 2016). However, Plasmodium species represent an exception to this rule. The percentage of polyA carrying transcripts in the genome exceeds $60 \%$ for most Plasmodium spp., including P. falciparum (64\%) (Djuranovic et al., 2018). The pervasive ribosomal stalling and frameshifting found on polyA tracks in other eukaryotes (Arthur et al., 2015; Koutmou et al., 2015; Tournu et al., 2019) would make it almost impossible for the majority of Plasmodium proteins to be efficiently and correctly synthesized. However, global studies of Plasmodium protein composition (Florens et al., 2002; Silvestrini et al., 2010) and protein synthesis (Le Roch et al., 2004; Bunnik et al., 2013; Caro et al., 2014) do not show any reduction in either the protein or mRNA abundances of polyA track genes. This suggests that both ribosomal stalling and frameshifting in Plasmodium are resolved by adaptations in protein synthesis and mRNA quality control systems. In this review, we will discuss how the extreme AT-rich genome of malaria-causing parasite promoted special features in $P$. falciparum ribosomes to enable translation of polyA tracks throughout the complete life cycle. Additionally, genomic changes and parasitic environment have also influenced variation in mRNA surveillance mechanism within the organism resulting in divergence from other Eukaryotes.

\section{EVOLUTION OF AT-RICHNESS IN P. falciparum}

Extremes in genomic base composition toward GC- or ATrichness exist in all domains of life (Sueoka, 1962; Wernegreen and Funk, 2004; Zilversmit et al., 2010; Wu et al., 2012). The extent of these extremes in nucleotide composition is limited by the necessity of all 20 amino acids and the subsequent requirement of all four nucleotides to encode them. As such, long homopolymeric amino acid repeats appear to be a characteristic of genomes with either bias (Glöckner, 2000; Albà et al., 2007; Muralidharan et al., 2011). Harboring either extreme AT- or GC-richness affects genomic structure, stability, transcriptome, and codon bias of organisms (Wu et al., 2012). As seen in Table 1, the P. falciparum mean AT-richness of around $80 \%$ appears to be one of the highest in all Eukaryotes (Pollack et al., 1982; Musto et al., 1999; Gardner et al., 2002a; Videvall, 2018). Surprisingly, the higher AT-content of the P. falciparum genome cannot be fully explained by increased AT-richness in intergenic regions, but rather by contributions of AT-richness in both coding $76.22 \%$ (Table 1) and non-coding genome 90\% (Gardner et al., 2002a). Overall, gene organization patterns in $P$. falciparum are not influenced by the AT-bias (Glöckner, 2000; Szafranski et al., 2005; Djuranovic et al., 2018). However, what distinguishes Plasmodium species from other AT-rich organisms is distribution of consecutive adenosine nucleotides resulting in unusually high percentage of polyA track genes (Table 2). The genomes of $P$. falciparum and related Plasmodium species have apparently evolved independently to reach extreme AT-bias (Table 2). Interestingly, while the two groups of Plasmodium species can be separated based on their AT-genomic content (median of $75 \%$ versus a median of $55 \%$ AT-richness), both groups accommodate a considerable amount of polyA tracks within the coding regions (Djuranovic et al., 2018).

Perhaps just as interesting as the consequences of genomic base composition biases are the factors driving it. Previous studies in $P$. falciparum were unable to conclude the primary role of 


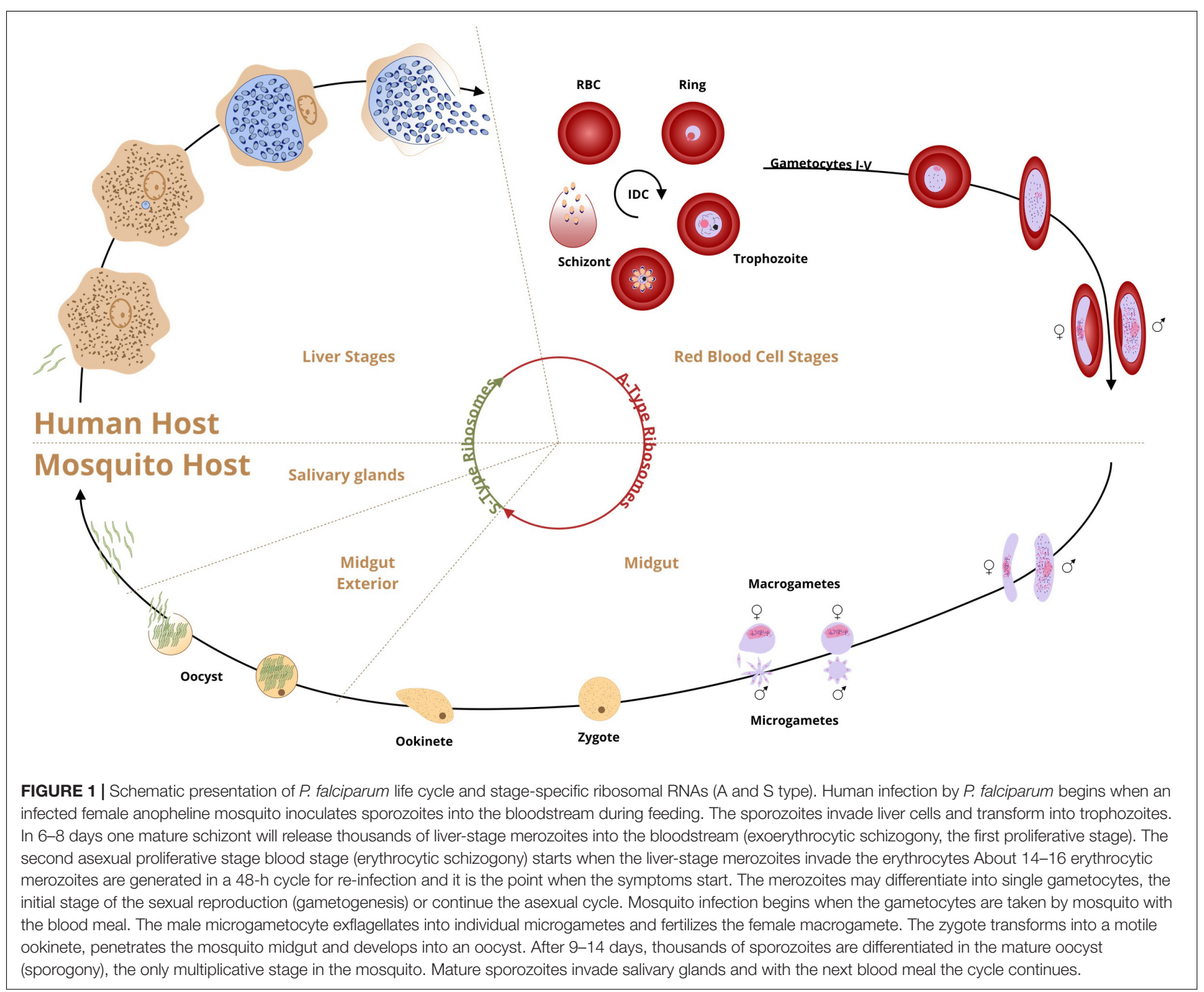

homopolymeric amino acid repeats in the parasite proteome (Muralidharan et al., 2011; Muralidharan and Goldberg, 2013). Nutrient availability to intracellular parasites - as well as endosymbionts - appears to be a major factor in driving ATrichness, particularly nitrogen availability (Seward and Kelly, 2016; Dietel et al., 2019). De novo synthesis of nucleotides comes at great metabolic expense, especially regarding $\mathrm{G}+\mathrm{C}$ nucleotides (Dietel et al., 2019). A+T nucleotides are less metabolically costly to create and tend to be more abundant. Consequently, $\mathrm{A}+\mathrm{T}$ nucleotides are easier to scavenge, even in intracellular environments where nutrients may not be readily available. In the case of $P$. falciparum, where de novo synthesis of purines does not occur, the parasites must rely upon purine scavenging and salvage pathways (Ting et al., 2005; El Bissati et al., 2006; Quashie et al., 2008). Conversely, pyrimidine de novo synthesis occurs using glutamine and aspartic acid precursors. This appears to be the main source for these nucleotides, with the folate pathway being required for thymidine production (Sherman, 1979; Cassera et al., 2011; Hamilton et al., 2017). However, unlike other intracellular organisms referenced above, the intracellular environment for $P$. falciparum is not necessarily nutrient poor, but perhaps nutrient selective; particularly prior to parasite augmentation of the host cell. While $P$. falciparum has multiple means by which amino acids are obtained, much of its initial amino acid supply is from proteolysis of human host red blood cell hemoglobin (Leiriao et al., 2004; Liu et al., 2006; Babbitt et al., 2012).

This brings us to a second major contributor of AT-richness in intracellular organisms: oxidative stress. Reactive nitrogen (RNS) and reactive oxygen species (ROS) generate oxidative stress resulting in 8-oxoguanine production via guanine oxidation. If left unrepaired in DNA, 8-oxoG is able to pair with adenosine; ultimately causing a $\mathrm{G}: \mathrm{C}$ to $\mathrm{T}: \mathrm{A}$ conversion. Compounding the process, hemoglobin degradation produces free heme and $\mathrm{H}_{2} \mathrm{O}_{2}$, which generates further oxidative stress for the parasite (Becker et al., 2004). Additionally, NO and other RNS species may be important factors in the soluble heme-hemozoin equilibration (Ostera et al., 2011). Interestingly, another erythrocytic parasite from Apicomplexa phylum, Babesia microti, does not degrade 
hemoglobin and has a considerably less AT-rich genome (61.02\%) and polyA tracks (2.17\% of genes with polyA tracks) compared to P. falciparum (Cornillot et al., 2012; Djuranovic et al., 2018). Although Plasmodium spp. does supply some of its own antioxidants to cope with oxidative assault, the higher than expected $\mathrm{G}: \mathrm{C}$ to $\mathrm{T}: \mathrm{A}$ conversion in the organism suggests a lack of full compensation by the biochemical and/or DNA repair safeguards (Hamilton et al., 2017). While 8-oxoG could potentially result in AT-richness imprinted in the DNA sequence, it causes more problems when found in RNA (Simms and Zaher, 2016). The oxidative lesion and incorporation of 8oxoG in mRNAs reduces the rate of peptide-bond formation by more than three orders of magnitude (Simms et al., 2014). The effect of 8-oxoG nucleotides in mRNAs is independent of its position within the codon, results in stalling of the translational machinery, and finally activation of No-Go decay mRNA surveillance mechanisms (Simms et al., 2014). As such, the presence of oxidative stress may have driven both an increase in genomic AT-richness and changes in mRNA surveillance mechanisms of $P$. falciparum; which are discussed further below.

AT-richness itself appears to provide a feedback loop in the parasite with its increased indel rates, which are thought to be due to DNA replication slippage on AT repeats. These AT tracks provide amplicon breakpoints for copy number variant (CNV) alteration via non-allelic homologous repair-like mechanism that can be advantageous in altering resistance gene CNV numbers (Guler et al., 2013; Hamilton et al., 2017; Huckaby et al., 2019). Altogether, metabolic and biochemical factors continuously drive

TABLE 1 | Comparison of AT-richness and polyA track gene ratios over selected Eukaryotic species.

\begin{tabular}{lcc}
\hline Organism & CDS \% AT richness & PolyA track genes \\
\hline Plasmodium falciparum & $76.22 \%$ & $63.54 \%$ \\
Plasmodium reichenowi & $75.93 \%$ & $62.93 \%$ \\
Dictyostelium discoideum & $72.57 \%$ & $20.96 \%$ \\
Tetrahymena thermophila & $72.50 \%$ & $28.19 \%$ \\
Saccharomyces cerevisiae & $60.39 \%$ & $5.51 \%$ \\
Plasmodium knowlesi & $59.77 \%$ & $41.42 \%$ \\
Caenorhabditis elegans & $57.94 \%$ & $1.93 \%$ \\
Plasmodium vivax & $53.51 \%$ & $38.85 \%$ \\
Drosophila melanogaster & $50.66 \%$ & $1.10 \%$ \\
Pan troglodytes & $50.60 \%$ & $2.17 \%$ \\
Homo sapiens & $49.98 \%$ & $1.40 \%$ \\
Trypanosoma brucei & $49.19 \%$ & $2.89 \%$ \\
Trypanosoma cruzi & $46.83 \%$ & $2.74 \%$ \\
Toxoplasma gondii & $42.88 \%$ & $1.01 \%$ \\
Leishmania donovani & $37.63 \%$ & $0.19 \%$ \\
Leishmania major & $37.52 \%$ & $0.05 \%$ \\
Leishmania infantum jpcm5 & $37.50 \%$ & $0.12 \%$ \\
Acanthamoeba castellanii str neff & $37.06 \%$ & $0.11 \%$ \\
Emiliania huxleyi & $31.38 \%$ & $0.10 \%$ \\
Aureococcus anophagefferens & $29.37 \%$ & $0.33 \%$ \\
\hline The coding region AT-richness & & \\
\hline & & \\
\hline
\end{tabular}

The coding region AT-richness from a relevant selection of organisms with high, moderate, and low AT-content was compiled from Habich (2016) and Videvall (2018) and sorted in descending order. the parasite genome toward AT richness, which, in turn, drives indels that potentiate genomic plasticity providing an overall platform for relatively rapid adaptive evolution in the parasite. Unarguably, these factors necessitate increased fidelity in DNA replication and RNA transcription. While the exact details specific to Plasmodium spp. evolutionary adaptation toward an AT-rich genome, unique codon biases, and polyA encoded lysine stretches remains to be explored, the role ribosomes play as influential factors in this process is certain.

\section{THE RRNA AND SPECIALIZED RIBOSOMES OF Plasmodium}

The most abundant genes in cells and genomes from bacteria to eukaryotes are those encoding ribosomal RNA. Ribosomal RNA genes in eukaryotic cells form clusters with a highly repetitive structure. S. cerevisiae, a single cell organism, has 150 rDNA repeats in one cluster on chromosome XII, while human cells contain five clusters of approximately 70 rDNA

TABLE 2 | Comparison of AT-Richness and polyA track gene ratios over selected Plasmodium species.

\begin{tabular}{lcc}
\hline Organism & $\begin{array}{c}\text { CDS \% AT } \\
\text { richness }\end{array}$ & $\begin{array}{c}\text { PolyA track } \\
\text { genes }\end{array}$ \\
\hline Plasmodium gallinaceum & $78.81 \%$ & $71.77 \%$ \\
Plasmodium relictum & $78.43 \%$ & $79.18 \%$ \\
Plasmodium berghei & $76.26 \%$ & $68.26 \%$ \\
Plasmodium yoelii 17x & $77.03 \%$ & $64.96 \%$ \\
Plasmodium falciparum & $76.22 \%$ & $63.54 \%$ \\
Plasmodium chabaudi & $74.46 \%$ & $63.37 \%$ \\
Plasmodium reichenowi & $75.93 \%$ & $62.93 \%$ \\
Plasmodium vinckei petteri & $74.91 \%$ & $62.58 \%$ \\
Plasmodium gaboni & $77.56 \%$ & $61.76 \%$ \\
Plasmodium falciparum camp malaysia & $76.71 \%$ & $61.02 \%$ \\
Plasmodium falciparum nf54 & $76.55 \%$ & $60.60 \%$ \\
Plasmodium falciparum fch 4 & $76.67 \%$ & $60.57 \%$ \\
Plasmodium falciparum ugt5 1 & $76.49 \%$ & $60.45 \%$ \\
Plasmodium falciparum santa lucia & $76.75 \%$ & $60.42 \%$ \\
Plasmodium falciparum palo alto uganda & $76.56 \%$ & $60.33 \%$ \\
Plasmodium falciparum nf135 5 c10 & $76.56 \%$ & $59.98 \%$ \\
Plasmodium falciparum malips096 e11 & $76.50 \%$ & $59.81 \%$ \\
Plasmodium falciparum 7g8 & $76.65 \%$ & $59.72 \%$ \\
Plasmodium yoelii yoelii & $75.20 \%$ & $51.06 \%$ \\
Plasmodium knowlesi & $59.77 \%$ & $41.42 \%$ \\
Plasmodium knowlesi strain h & $59.76 \%$ & $41.42 \%$ \\
Plasmodium vivax & $53.51 \%$ & $38.85 \%$ \\
Plasmodium inui san antonio 1 & $57.91 \%$ & $33.83 \%$ \\
\hline Plasmodium sop. coding $\%$ & $31.12 \%$ \\
\hline
\end{tabular}

Plasmodium spp. coding region AT-content and the ratio of polyA affected transcripts was collected (Habich, 2016; Videvall, 2018). The data are organized in the table to demonstrate a separation of two groups with high and low coding region AT-content and subsequently the number of polyA track containing transcripts. The separation notably occurs along the line of geographic region with the high AT-content organisms being predominantly found in Africa and the low AT-content group in Asia, Southeast Asia, and Latin America. However, the low AT-content group still exceeds that of most organisms. 
repeats on five different chromosomes (Sakai et al., 1995). The organization of rDNA genes in clusters is conserved among most of the eukaryotic organisms (Kobayashi, 2014). Transcription of these clusters is highly coordinated to meet the huge demand for ribosomes, which occupy $\sim 50 \%$ of the total protein mass in a cell (Warner, 1999). Plasmodium genomes, however, have only 4-8 single copy rDNA units that are encoded on different chromosomes (Gunderson et al., 1987; Waters et al., 1989; Li et al., 1997). Such a small number of rDNA copies throughout the genome is seen elsewhere only in bacteria. E. coli has seven ribosomal RNA genes spread over its circular genome and well positioned in the regions near an origin of replication. This arrangement in E. coli enables maximum ribosomal RNA transcription while preventing possible collisions between replication forks and transcription machinery (Ellwood and Nomura, 1982). Thus, while most of the other organisms have optimized ribosome production, how the malaria-causing parasite produces its significant ribosome numbers is still unknown. It might be possible that massive DNA replication that occurs throughout its lifecycle (during shizogeny) in both hosts may accommodate the rRNA production requirements.

Besides this unusual rDNA arrangement, malaria parasites are pioneers in the new era of specialized ribosomes (Walliker et al., 1987; McCutchan et al., 1988; Waters et al., 1989; Velichutina et al., 1998; Xue and Barna, 2012). Plasmodium spp. has structurally distinct, stage-specific ribosomes and are the most well-known case of rRNA heterogeneity (McCutchan et al., 1988). The difference in sequence and expression profile during the life cycle classified them into A-type (asexual stage specific) and S-type (sporozoite specific) in the majority of Plasmodium species, including $P$. falciparum; with $P$. vivax having a third O-type rRNA (Li et al., 1997). The A-type is present in the liver and blood stage and S-type is sporozoite specific rRNA type that emerges during the mosquito stage and ends during the parasite development in hepatocytes (Zhu et al., 1990). Here, we will focus on the process by which the ribosome types switch and whether ribosomes with distinct rRNA play a selective role in the mRNAs they translate.

Plasmodium spp. have adapted to translation in two different hosts. This requires translation optimization at two distinct temperatures, one of which can be highly variable depending on the mosquito environment. Even though one would think that changes in temperature and hosts would be the reason for development of different rRNAs, the presence of A-type during the early mosquito stage and S-type during early liver stage does not support that idea (Fang and McCutchan, 2002). The rRNA sets are not expressed in an exclusive and binary (on/off) fashion, but more as a dynamic, heterogeneous population whereby one subtype, A or S, is the more dominant rRNA type in a particular lifecycle stage. While the idea of a thermoregulatory nature of the rRNA units has been explored earlier in $P$. berghei, rodent malaria, it has not been followed since (Fang and McCutchan, 2002). P. berghei, contains four distinct copies off the rRNA (A, B, C, D) and they are divided into A-type (A and B) and S-type (C and D). A single copy of the S-type gene, $\mathrm{C}$ or $\mathrm{D}$ was sufficient for life cycle completion, which only affected the parasite fitness. The group was unable to disrupt both S-type genes simultaneously; nor could they disrupt either of A-type genes (van Spaendonk et al., 2001). Interestingly, authors noticed growth retardation in oocyst development, which was more pronounced in $\mathrm{D}$-unit disruption rather than in C-unit (van Spaendonk et al., 2001). Such difference could be explained by difference in ribosomal levels stemming from different transcriptional levels of $\mathrm{C}$ - and $\mathrm{D}$-units or functional diversity of $\mathrm{C}$ - and $\mathrm{D}$-unit containing ribosomes (Xue and Barna, 2012; Mills and Green, 2017). The disruption of specific S-type rRNA is also associated with oocyst development defects in the second rodent parasite $P$. yoelii (Qi et al., 2015). Finally, van Spaendonk et al. (2001) note a lack in differences between core catalytic components (e.g., GTPase center) of the ribosome large subunit in $P$. berghei that were previously described in P. falciparum (Velichutina et al., 1998). These results among species of Plasmodium potentiate the question of some aspect of ribosomal specialization (Vembar et al., 2016a).

Previous bacterial work has shown changes in rRNA operon expression in response to stress, resulting in phenotypic changes (Kurylo et al., 2018). The change in Plasmodium spp. rRNA population dynamics in response to environmental stress from host transfer is reminiscent of the bacterial changes in rRNA operon expression. However, whether changes in ratios of Plasmodium spp. rRNA types drive phenotypic changes is still unknown. Ostensibly, the ribosomes share the same repertoire of ribosomal proteins. RNAseq data shows that while ribosomal protein gene transcription as a whole is fairly persistent throughout the complete life cycle of $P$. falciparum, oscillations in their overall expression pattern match that of stages with increased protein synthesis (Figure 2). This does not exclude the highly sought-after notion that a specific set of ribosomes may be optimized for specific mRNA substrates or cell populations that may also exist in Plasmodium spp. A recent study in zebrafish showed that embryos have different subtypes of $5.8 \mathrm{~S}, 18 \mathrm{~S}$, and $28 \mathrm{~S}$ rRNAs, creating similar ribosome diversity seen in Plasmodium cells (Locati et al., 2017). In silico data have shown that the expanded regions of $18 \mathrm{~S}$ subunit expressed in zebrafish embryos may preferentially bind maternal transcripts when compared to somatic subtypes (Locati et al., 2017). Similarly, a shift in the expression of $16 \mathrm{~S}$ rRNA ribosome variants created populations of $E$. coli cells that accommodated functional differences in tetracycline binding (Kurylo et al., 2018). As was mentioned before, the rRNA heterogeneity that was mostly known in Plasmodium parasites (Gunderson et al., 1987; Waters et al., 1989; Zhu et al., 1990; Rogers et al., 1996; Xue and Barna, 2012) is now recognized in other organisms (Locati et al., 2017; Kurylo et al., 2018). However, the role of different Plasmodium rRNAs as a response to different environmental conditions is still not defined.

\section{Plasmodium RIBOSOMES, POLYA AND POLY-LYSINE SEQUENCES}

Regardless of the host, all Plasmodium spp. rRNA types must contend with the translation of unusually high AU-content and long-coding polyA stretches in mRNAs. RNA-seq data 


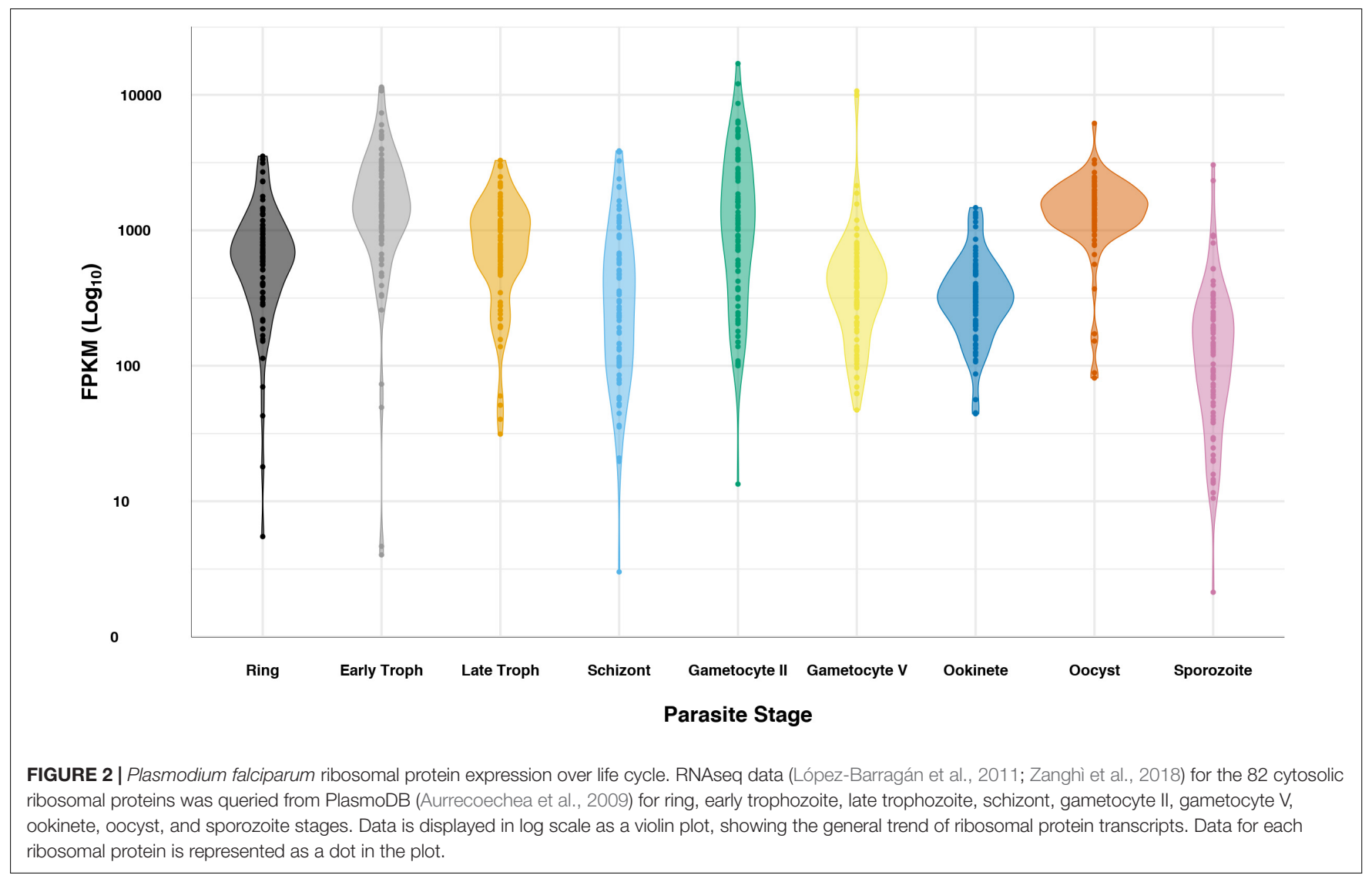

(Le Roch et al., 2004; Shock et al., 2007; Bunnik et al., 2013; Guler et al., 2013; Caro et al., 2014) indicates that the mRNA levels of genes containing polyA stretches follows the same trend as the general gene expression for all stages in both hosts (Figures 3A-D). We can conclude that both types of ribosomes expressed in both hosts have features allowing efficient translation of transcripts containing long, coding polyA tracks. This indicates that $P$. falciparum ribosomes have higher fidelity during translation of polyA sequences and are able to accommodate long polybasic peptides coming through their protein-exit channel. Previous ribosome mutagenesis studies in S. cerevisiae suggested functional differences in the GTPase centers of $P$. falciparum A- and S-type ribosomes (Velichutina et al., 1998). Despite the differences in yeast viability and growth rates, chimeric yeast ribosomes with either Plasmodium's A- or S-type GTPase centers exhibited increased translational accuracy (Velichutina et al., 1998). Even though there are stage-specific ribosomes, there is a group of genes that is present in human and mosquito that contain polyA tracks (Figure 4). More recently it was also shown that the P. falciparum ribosomes have been altered to accommodate the poly-lysine patches that are prolific throughout the proteome (Djuranovic et al., 2018). To allow these low-complexity, homopolymeric and polybasic amino acid repeats, the parasite ribosome exit channel has been altered by increasing the channel size at key bottle necks, as well as a reduction in the hydrophobicity patches typically seen in bacterial, yeast, or human ribosomes (Djuranovic et al., 2018).
Ribosome profiling and biochemical assays suggest an increased or modified fidelity such that parasite ribosomes do not stall or frameshift on polyA tracks (Djuranovic et al., 2018). The mechanism of this altered fidelity may result from not only modification of the ribosomal RNA sequence, but also via changes to key protein components of ribosomes. Two $P$. falciparum ribosome cryoEM structures suggest a reduced or lost interaction of the receptor for activated C kinase 1 (RACK1) to Plasmodium ribosomes (Wong et al., 2014; Sun et al., 2015). RACK1 has been established as an integral ribosomal scaffold protein (Sengupta et al., 2004). Beside other non-ribosome associated functions, RACK1 was found to be important for cap-dependent translation initiation, IRES-mediated translation, and site-specific translation (Majzoub et al., 2014). RACK1 also contributes to the translation arrest that is induced by translation of polyA sequences (Dimitrova et al., 2009; Kuroha et al., 2010), CGA-CGA codons in yeast (Wolf and Grayhack, 2015), or runs of consecutive basic amino-acid (Kuroha et al., 2010). Stalls on polyA tracks can be resolved in mammalian cells by deletion of RACK1 and ZNF598, thus enabling read-through of stall-inducing sequences (Garzia et al., 2017; Juszkiewicz and Hegde, 2017; Sundaramoorthy et al., 2017). S. cerevisiae ribosomes lacking the RACK1 homolog Asc1 are able to translate through the CGA-CGA stalling sequences and increase normally attenuated protein output (Wolf and Grayhack, 2015). The increase in amount of synthesized protein from CGACGA sequences is a consequence of overall reduced elongation 

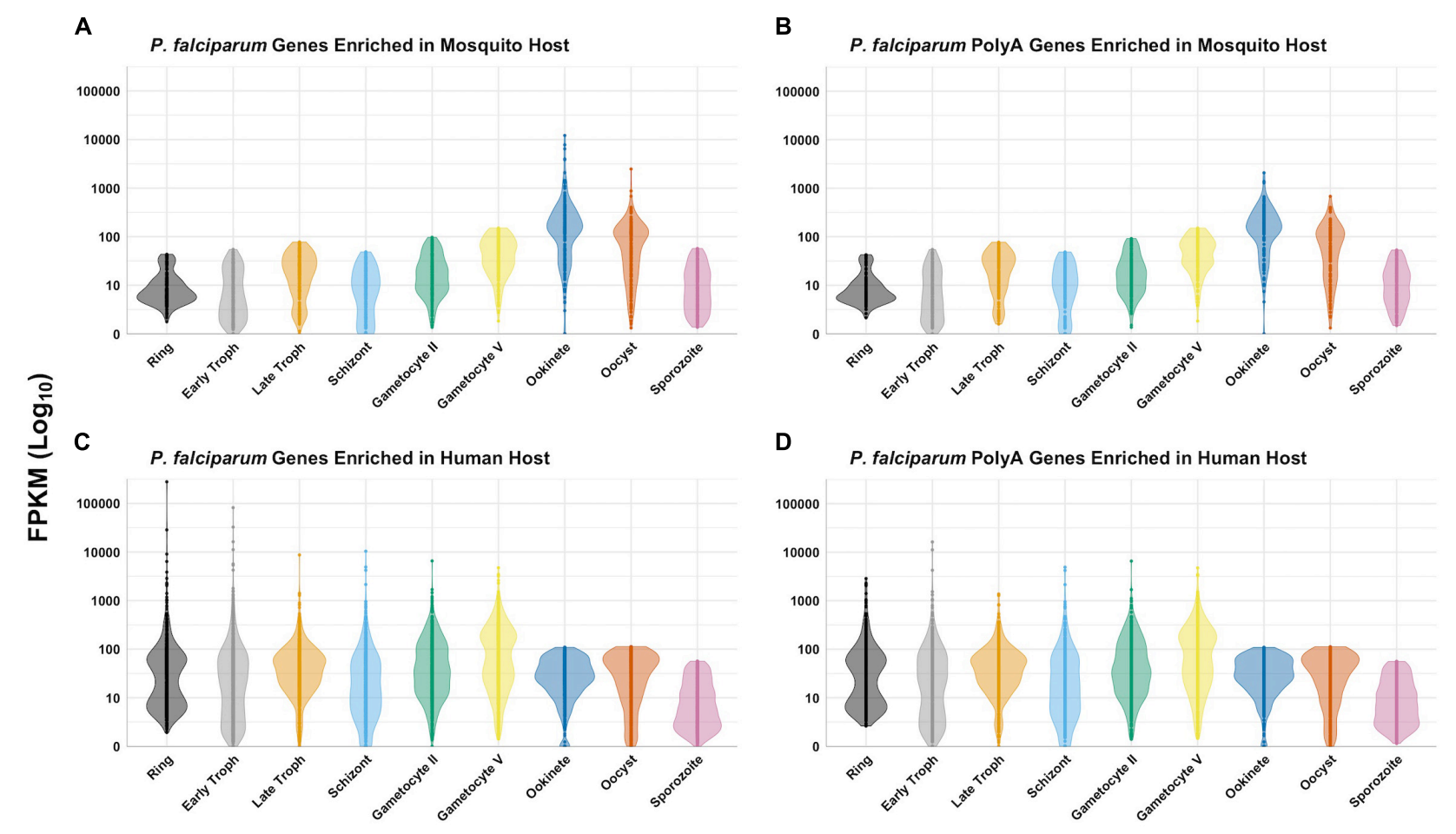

Parasite Stage

FIGURE 3 | Expression of P. falciparum genes in different hosts. The data was queried from PlasmoDB (Aurrecoechea et al., 2009; López-Barragán et al., 2011; Zanghì et al., 2018) for protein-coding genes with expression data greater than or equal to the 80th percentile for ring, early trophozoite, late trophozoite, schizont, gametocyte II, gametocyte V, ookinete, oocyst, and sporozoite stages. P. falciparum genes enriched in the mosquito host (A), human host (C), and polyA genes for each (B and $\mathbf{D}$, respectively) are as previously defined. RNAseq data for all stages in both hosts for these gene sets are displayed in log scale as a violin plot with all data points for comparison.

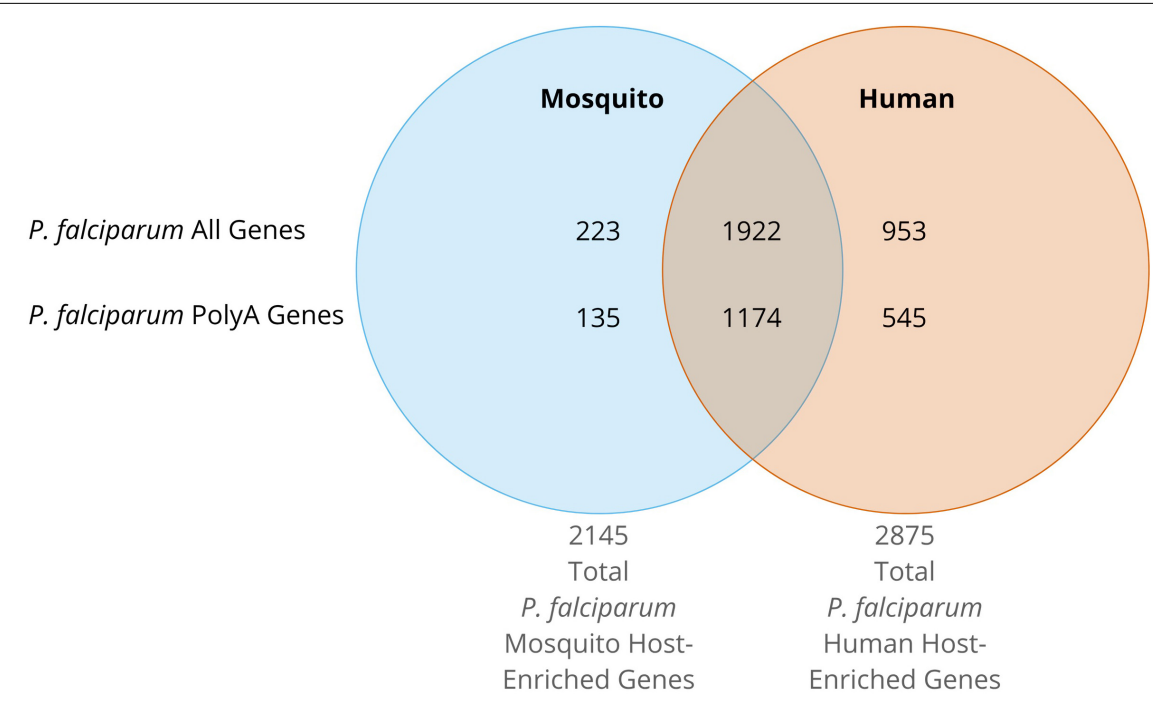

FIGURE 4 | Venn Diagram of $P$. falciparum gene expression from RNAseq data. The expression data greater than or equal to the 80th percentile for ring, early trophozoite, late trophozoite, schizont, gametocyte II, gametocyte V, ookinete, oocyst, and sporozoite stages was queried (López-Barragán et al., 2011; Zanghì et al., 2018). Mosquito stage total genes were defined as those with expression data greater than or equal to the 80th percentile during gametocyte $V$, ookinete, oocyst, or sporozoite stages. Mosquito host-specific genes are defined as above, but solely in mosquito host stages. Total parasite genes expressed in the human host were defined as those with expression data greater than or equal to the 80th percentile during sporozoite, ring, early trophozoite, late trophozoite, schizont, gametocyte II, or gametocyte $V$ stages. Enriched parasite genes expressed in the human host are defined as above, but solely in human host stages. PolyA genes are those defined as having one or more runs of twelve or more consecutive adenosines in the coding region of the gene. 
rates of yeast ribosomes that lack Asc1 (Tesina et al., 2019). Slower elongation rates may also influence cellular responses to ribosome pausing. The position of RACK1/Asc1 near the mRNA exit channel on the ribosome could be important in sensing ribosome collisions that lead to activation of ribosome rescue and mRNA surveillance pathways (Kim et al., 2014; Simms and Zaher, 2016; Tesina et al., 2019). The fact that Plasmodium ribosomes lack interaction with PfRACK1 could be beneficial for translation of polyA tracks into poly-lysine runs. However, based on previous conclusions concerning the role of RACK1/Asc1 in correct reading frame maintenance during translation of stalling sequences, the majority of polyA coding sequences in malaria parasites would be predicted to have multiple frameshifted protein products.

Previous studies (Lu and Deutsch, 2008; Kuroha et al., 2010; Brandman et al., 2012) proposed that stalling during the translation of polyA tracks is due to synthesis of the polylysine rich nascent peptide. Electrostatic interactions of the polybasic peptide and the peptide exit tunnel in the ribosome would elicit ribosomal stalling (Lu and Deutsch, 2008). Recent studies revealed that an mRNA-mediated mechanism is directly contributing to stalling (Arthur et al., 2015; Koutmou et al., 2015; Tesina et al., 2019). Consecutive adenosines are engaged by the ribosome decoding center nucleotides, are stabilized on both sides by rRNA base stacking interactions (Tesina et al., 2019), and adopt a helical conformation typical for single stranded polyA stretches (Tang et al., 2019). PolyA tracks are highly efficient at causing ribosome stalling, and the inhibitory conformation of polyA mRNA bases can further contribute to a polyA-mediated stalling mechanism. This conclusion is in line with the previous observations that consecutive AAG codons are less efficient at causing stalling than AAA codons (Arthur et al., 2015; Koutmou et al., 2015), despite coding for the same amino acid. Altogether, the charge and conformation of the poly-lysine nascent chain in conjunction with the stacked polyA mRNA nucleotides in the decoding center of the ribosome contribute to the overall stalling mechanism (Tesina et al., 2019). P. falciparum ribosomes are again the exception to this rule. The nucleotides that make stacking interactions with polyA repeats are conserved in $P$. falciparum ribosomes. However, both endogenous transcripts and reporter sequences with long runs of polyA tracks are efficiently translated by Plasmodium (Lacsina et al., 2011; Bunnik et al., 2013; Djuranovic et al., 2018). Thus, in order to adapt to polyA track translation for production of the polybasic and homopolymeric lysine repeats, the malaria-causing parasite has altered the sequence of its rRNA, its ribosome structure, its ribosomal proteins, and its mRNA translation quality control pathways.

\section{mRNA SURVEILLANCE PATHWAYS IN AU-RICH TRANSCRIPTOME OF P. falciparum}

The core elements for mRNA translation are highly conserved in Plasmodium spp. (Vembar et al., 2016a). The unique features involving protein synthesis in Plasmodium, such as different types of ribosomes in different life cycle stages, were noticed even before genome sequencing of the malaria parasite (Gunderson et al., 1987; Zhu et al., 1990; Rogers et al., 1996; van Spaendonk et al., 2001). However, the presence of an unusual number of mRNA binding proteins and the absence of some elements of mRNA surveillance mechanism were noticed upon completion of the P. falciparum genome sequence (Gunderson et al., 1987; Waters et al., 1989; Rogers et al., 1996; van Spaendonk et al., 2001; Le Roch et al., 2004; Bunnik and Le Roch, 2013; Cui et al., 2015; Reddy et al., 2015; Lu et al., 2017). A recent review elaborated on the translational regulation in blood-stages of malaria parasites (Vembar et al., 2016a). They focused on cytoplasmic mRNA translation and the fate of mRNAs: decoding of the mRNA messages by the $80 \mathrm{~S}$ ribosomes, degradation of mRNAs by exo- or endo-nucleases (mRNA decay), and sequestration of mRNAs by protection from mRNA decay or by inhibition of translation. We focus here on the mechanism of activation of mRNA surveillance pathways by aberrant mRNAs in the context of unusual AU-richness and abundance of polyA tracks in Plasmodium transcriptome.

Eukaryotic cells have developed mechanisms to protect themselves from the production of the possible toxic proteins due to aberrant mRNA translation events. There are three mRNA quality control systems for translational errors in eukaryotes: Non-sense mediated decay (NMD), No-Go decay (NGD), and Non-Stop decay (NSD). NMD targets transcripts harboring "premature" termination codons (PTC) and nascent polypeptide chains synthesized from such transcripts for efficient degradation (Shoemaker and Green, 2012). Components of NMD pathway distinguishes PTCs from authentic stop codons in the coding sequence. PTCs are usually the product of point-non-sense mutations, ribosomal frameshifting on slippery sequences, aberrant splicing events, or in some cases, the consequence of targeted gene regulation through alternative splicing (Sorber et al., 2011; Yeoh et al., 2019). In higher eukaryotes, PTCs are generally recognized by their proximity to so-called exon-junction complexes (EJCs), which are deposited near exon junctions during pre-mRNA splicing in the nucleus (Shoemaker and Green, 2012).

No-Go decay is an "umbrella term" for the mRNA surveillance pathway that deals with either damaged or difficult to translate mRNA sequences that cause the ribosome to stall during the elongation cycle of translation. Besides the previously mentioned mRNA base damages (8-oxoG) (Simms et al., 2014; Simms and Zaher, 2016), mRNA translation can be stalled by lack of aminoacylated-tRNAs, strong mRNA secondary structure (i.e., stem-loops or long GC-rich regions), or stable interaction of the nascent polypeptide chain with the translating ribosome. Even though Non-Stop Decay (NSD) was discovered earlier than NGD (Doma and Parker, 2006; Izawa et al., 2012; Tsuboi et al., 2012; Saito et al., 2013; Martin et al., 2014; Guydosh and Green, 2017), it became apparent that in mammals and higher eukaryotes, the NSD and NGD pathways share the same effector protein complexes (Saito et al., 2013). The NSD targeted mRNAs that originate from premature $3^{\prime}$ adenylation or cryptic polyadenylation signals found in coding sequences indeed represent a similar group of transcripts that would be 
targeted by NGD pathway (Saito et al., 2013; Kashima et al., 2014; Martin et al., 2014). Ribosomes that translate mRNAs without stop codons would eventually stall while translating long polyA tails into poly-lysine repeats, or because they would simply run out of message. Recognition of these types of transcripts, as well as the aforementioned NGD targets, trigger components of NGD/NSD pathways resulting in targeted mRNA cleavage and degradation.

The majority of mRNA surveillance pathway genes have been annotated in the P. falciparum genome (Table 3; Hughes et al., 2010). However, there are no mechanistic studies to confirm the activity of these pathways. Most of our knowledge on Plasmodium's mRNA surveillance pathways comes from bioinformatic searches using homologous sequences from other eukaryotes. An indirect proof of the existence of NMD in Plasmodium is through the studies of alternative splicing of pre-mRNA (Sorber et al., 2011; Yeoh et al., 2019). Regulated alternative splicing events generating transcripts that do not lead to apparent protein synthesis usually carry PTCs, and thus are committed to NMD. Alternative splicing in $P$. falciparum has been reported for several genes like delta-aminolevulinic acid dehydratase (ALAD), stromal processing peptidase (SPP), and chloroquine resistance transporter (PfCRT); among the others. Additionally, studies on the essentiality of Plasmodium genes that use the CRISPR/Cas9 technique (Ghorbal et al., 2014) or transposon techniques (Zhang et al., 2018) rely partially on silencing targeted genes through the activation of NMD. In this case, activation of NMD is the consequence of either mutations that are generated during CRISPR/Cas9 DNA cleavage, transposon insertion in the coding sequence, or due to aberrant splicing events caused by transposons landing in introns of targeted genes. As noted above, more than $60 \%$ of the $P$. falciparum transcripts harbor polyA track motifs that are seen as mRNA "slippery" sequences during translation
(Habich, 2016; Djuranovic et al., 2018). Translation of runs of poly-adenosine nucleotides results in ribosomal frameshifting in most tested organisms causing activation of NMD pathways (Arthur et al., 2015; Koutmou et al., 2015). However, ribosome profiling (Lacsina et al., 2011; Bunnik et al., 2013) and reporter assays (Djuranovic et al., 2018) indicate that $P$. falciparum ribosomes maintain fidelity during translation of rather long polyA stretches (more than 36As in a row). Therefore, while there is indirect evidence that the NMD pathway exists in Plasmodium, it seems that this pathway is not upregulated during Plasmodium ribosomes' interactions with its polyA runs and AUrich coding sequences. The most probable reason for this is the above mentioned changes in ribosome structure and fidelity.

Genomic sequencing has also revealed several critical components of surveillance pathways that are missing. According to NCBI, KEGG, and plasmoDB databases, $P$. falciparum and the majority of other Plasmodium spp. lack the NGD and NSD decay pathways components Hbs1 (Doma and Parker, 2006) and Cue2-RNA endonuclease (D'Orazio et al., 2019). With the exception of $S$. cerevisiae, the Hbs1/Pelo protein complex rescues stalled ribosomes on mRNAs. It was postulated that stalling events cause ribosome collisions (Simms et al., 2017), generating unique disome units consisting of the stalled ribosome and the following colliding ribosome (Beckman and Inada). The disome, as a minimal ribosome collision unit, is recognized by Ribosome-associated Quality Control (RQC) and NGD pathways (Ito-Harashima et al., 2007; Izawa et al., 2012; Tsuboi et al., 2012; Guydosh and Green, 2017; Juszkiewicz and Hegde, 2017). Activation of RQC and NGD leads to cleavage of stalled mRNA by Cue2, and possibly other unknown endonucleases, which ultimately leads to ribosome rescue by the activity of the Pelo/Hbs1 complex (Ito-Harashima et al., 2007; Tsuboi et al., 2012; Kashima et al., 2014; Matsuda et al., 2014; Sugiyama et al., 2019). In most of the above mentioned RQC and NGD studies,

TABLE $\mathbf{3}$ | Comparison of translation quality control factors in P. falciparum and its mosquito and human hosts.

\begin{tabular}{|c|c|c|c|}
\hline Pathway & H. sapiens & A. gambiae & P. falciparum \\
\hline NMD & $\begin{array}{l}\text { eRF1, eRF3, UPF1, UPF2, } \\
\text { UPF3AUPF3B, elF4AIII, } \\
\text { MLN51, Y14/MAGOH, BTZ, } \\
\text { SMG1, SMG5, SMG6, SMG7, } \\
\text { PP2, Musashi, PABP1 }\end{array}$ & $\begin{array}{l}\text { eRF1 (AGAP010310), eRF3 (AGAP009310), UPF1 } \\
\text { (AGAP001133), UPF2 (AGAP000337), UPF3 } \\
\text { (AGAP006649), elF4AIII (AGAP003089), Y14 } \\
\text { (AGAP006365)/MAGOH (AGAP010755), } \\
\text { SMG1(AGAP000368), SMG5 (AGAP008181), SMG6 } \\
\text { (AGAP000894), PP2A (AGAP004096), Musashi } \\
\text { (AGAP001930) }\end{array}$ & $\begin{array}{l}\text { UPF1 (PF3D7_1005500), UPF2 (PF3D7_0925800), } \\
\text { UPF3B (PF3D7_1327700), elF4Alll (PF3D7_0422700) } \\
\text { PF3D7_1327700), PP2A(PF3D7_0925400 - KEGG, } \\
\text { PF3D7_1319700 - Hs homology, or PF3D7_0927700 - } \\
\text { name), Musashi (PF3D7_0916700), PABP1 } \\
\text { (PF3D7_1224300), eRF1 (PF3D7_0212300), eRF3 } \\
\text { (PF3D7_1123400) }\end{array}$ \\
\hline NGD/NSD & $\begin{array}{l}\text { Pelota/HBS1L, RACK1, } \\
\text { ZNF598, N4BP2 (Cue2) }\end{array}$ & $\begin{array}{l}\text { Pelota (AGAP008269), HBS1L (AGAP002603), RACK1 } \\
\text { (AGAP010173), ZNF598 homolog (AGAP007725), } \\
\text { N4BP2 homolog (AGAP002516) }\end{array}$ & $\begin{array}{l}\text { Pelota (PF3D7_0722100), RACK1 (PF3D7_0826700), } \\
\text { ZNF598 (PF3D7_1450400) }\end{array}$ \\
\hline $\mathrm{RQC}$ & $\begin{array}{l}\text { CNOT4, ABCE1, TRIP4, } \\
\text { ASCC2, ASCC3, NEMF, } \\
\text { Listerin, UBE2D1, XRN1 }\end{array}$ & $\begin{array}{l}\text { CNOT4, ABCE1 (AGAP002182), ASCC2 homolog } \\
\text { (AGAP000428), ASCC3 (AGAP001234), NEMF homolog } \\
\text { (AGAP002680), Ltn1 (AGAP007143), UBE2D1 homolog } \\
\text { (AGAP000145), XRN1 }\end{array}$ & $\begin{array}{l}\text { ABCE1 (PF3D7_1368200), NEMF homolog } \\
\text { (PF3D7_1202600), Listerin homolog (PF3D7_0615600), } \\
\text { CNOT4 (PF3D7_1235300), ASCC3 homolog } \\
\text { (PF3D7_1439100), UBE2D1 homolog (PF3D7_1203900) } \\
\text { XRN1 (PF3D7_0909400) }\end{array}$ \\
\hline
\end{tabular}

Factors associated with NMD, NGD/NSD, and RQC pathways from the literature and KEGG pathway database in human cells were collected (Kanehisa et al., 2019).

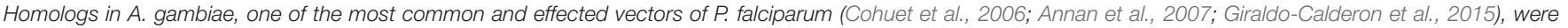

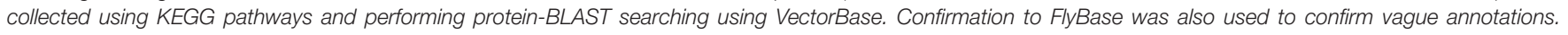

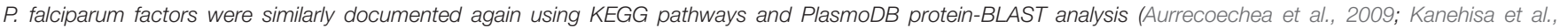

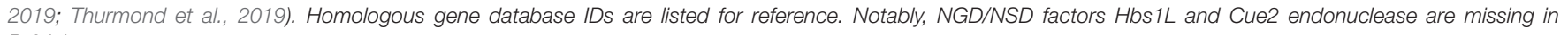
P. falciparum genome. 
a typical substrate for ribosomal stalling is a long polyA run, ranging from 36 to 60 adenosines, coding for a peptide with 1220 consecutive lysine residues. However, long polyA stretches in $P$. falciparum cells are efficiently translated into poly-lysine repeats (Lacsina et al., 2011; Bunnik et al., 2013). Of note, the longest endogenous polyA runs in different $P$. falciparum species range from 88 to 111 nucleotides and code for Plasmodium specific and hypothetical proteins (Habich, 2016), which is longer than the length of the normal $3^{\prime}$ polyA tail in either $S$. cerevisiae or human cells (Brown and Sachs, 1998; Chang et al., 2014; Subtelny et al., 2014). As such, many endogenous Plasmodium transcripts would be NSD targets in other eukaryotic organisms. It is also a question as to what the signal for NSD pathway is in Plasmodium as recent study on $3^{\prime}$ mRNA polyadenylation in apicomplexans did not find any differences in P. falciparum polyadenylation complex, polyA binding proteins, or polyA tails when compared to other species (Stevens et al., 2018; Kanehisa et al., 2019). Because Plasmodium lacks the components to rescue stalled ribosomes, and because Plasmodium ribosomes efficiently translate long polyA runs, the function and mechanism of the NGD/NSD pathway in $P$. falciparum remains a mystery.

\section{CONCLUSION}

While it may seem reasonable that $P$. falciparum adapted its ribosomes for higher fidelity on polyA runs and in parallel lost the ability to activate the RQC/NGD/NSD pathways, such a scenario is far from obvious. The absence of mRNA surveillance pathway components or deletion of RQC factors leads to both protein aggregation and proteotoxic stress in yeast cells (Choe et al., 2016; Yonashiro et al., 2016; Jamar et al., 2018). Protein aggregation is observed in P. falciparum in the absence of heat shock protein 110 (Muralidharan et al., 2012) but not due to the absence of mRNA surveillance or RQC pathways or as a consequence of increase

\section{REFERENCES}

Albà, M. M., Tompa, P., and Veitia, R. A. (2007). Amino acid repeats and the structure and evolution of proteins. Genome Dyn. 3, 119-130. doi: 10.1159/ 000107607

Annan, Z., Durand, P., Ayala, F. J., Arnathau, C., Awono-Ambene, P., Simard, F., et al. (2007). Population genetic structure of Plasmodium falciparum in the two main African vectors, Anopheles gambiae and Anopheles funestus. Proc. Natl. Acad. Sci. U.S.A. 104, 7987-7992. doi: 10.1073/pnas.0702715104

Arthur, L., Pavlovic-Djuranovic, S., Smith-Koutmou, K., Green, R., Szczesny, P., and Djuranovic, S. (2015). Translational control by lysine-encoding A-rich sequences. Sci. Adv. 1:e1500154. doi: 10.1126/sciadv.1500154

Aurrecoechea, C., Brestelli, J., Brunk, B. P., Dommer, J., Fischer, S., Gajria, B., et al. (2009). PlasmoDB: a functional genomic database for malaria parasites. Nucleic Acids Res. 37, D539-D543. doi: 10.1093/nar/gkn814

Babbitt, S. E., Altenhofen, L., Cobbold, S. A., Istvan, E. S., Fennell, C., Doerig, C., et al. (2012). Plasmodium falciparum responds to amino acid starvation by entering into a hibernatory state. Proc. Natl. Acad. Sci. U.S.A. 109, E3278E3287. doi: 10.1073/pnas.1209823109

Becker, K., Tilley, L., Vennerstrom, J. L., Roberts, D., Rogerson, S., and Ginsburg, H. (2004). Oxidative stress in malaria parasite-infected erythrocytes: host-parasite interactions. Int. J. Parasitol. 34, 163-189. doi: 10.1016/j.ijpara.2003.09.011 in both number or length of polyA tracks (Djuranovic et al., 2018). This conflicting result, along with the surprising lack of interaction between the ribosomal scaffold protein RACK1/Asc1 and Plasmodium ribosomes (Wong et al., 2014; Sun et al., 2015), argue that the mRNA surveillance pathways in $P$. falciparum are inherently different from those in other eukaryotes. The diversity of rRNAs, Plasmodium's ribosome structure, and the activity of yet unknown ribosome associated factors promote the possibility of "specialized ribosomes" in Plasmodium that allow for polyA tracks translation into functional proteins. Each of the aforementioned changes in parasites translational machinery and mRNA quality control pathways come at the cost of self-fitness that would normally be detrimental for survival of Plasmodium parasites in both humans and mosquitos. And yet the parasite has persisted in both of these hosts for hundreds of millions of years. Parasitologists and epidemiologists have wondered "How?" for decades; now as translational biologists, we add our voices to the same question.

\section{AUTHOR CONTRIBUTIONS}

All authors contributed equally to writing of this review.

\section{FUNDING}

This work in Djuranovic's lab was supported by NIH R01 GM112824 to SD and LEAP Awards to SD and SPD. JE was supported by NIH T32 GM007067 and NIMH R01 MH116999.

\section{ACKNOWLEDGMENTS}

We are thankful to Caitlin D. Hanlon for critical reading and suggestions on review topic.

Bowman, S., Lawson, D., Basham, D., Brown, D., Chillingworth, T., Churcher, C. M., et al. (1999). The complete nucleotide sequence of chromosome 3 of Plasmodium falciparum. Nature 400, 532-538.

Brandman, O., Stewart-Ornstein, J., Wong, D., Larson, A., Williams, C. C., Li, G. W., et al. (2012). A ribosome-bound quality control complex triggers degradation of nascent peptides and signals translation stress. Cell 151, 10421054. doi: 10.1016/j.cell.2012.10.044

Brown, C. E., and Sachs, A. B. (1998). Poly(A) tail length control in Saccharomyces cerevisiae occurs by message-specific deadenylation. Mol. Cell. Biol. 18, 65486559. doi: $10.1128 / \mathrm{mcb} \cdot 18.11 .6548$

Bunnik, E. M., and Le Roch, K. G. (2013). An introduction to functional genomics and systems biology. Adv. Wound Care 2, 490-498.

Bunnik, E. M., Chung, D. W., Hamilton, M., Ponts, N., Saraf, A., Prudhomme, J., et al. (2013). Polysome profiling reveals translational control of gene expression in the human malaria parasite Plasmodium falciparum. Genome Biol. 14:R128. doi: 10.1186/gb-2013-14-11-r128

Caro, F., Ahyong, V., Betegon, M., and DeRisi, J. L. (2014). Genome-wide regulatory dynamics of translation in the Plasmodium falciparum asexual blood stages. eLife 3:e04106. doi: 10.7554/eLife.04106

Cassera, M. B., Zhang, Y., Hazleton, K. Z., and Schramm, V. L. (2011). Purine and pyrimidine pathways as targets in Plasmodium falciparum. Curr. Top. Med. Chem. 11, 2103-2115. doi: 10.2174/156802611796575948 
Chang, H., Lim, J., Ha, M., and Kim, V. N. (2014). TAIL-seq: genome-wide determination of poly(A) tail length and $3^{\prime}$ end modifications. Mol. Cell. 53, 1044-1052. doi: 10.1016/j.molcel.2014.02.007

Choe, Y. J., Park, S. H., Hassemer, T., Korner, R., Vincenz-Donnelly, L., HayerHartl, M., et al. (2016). Failure of RQC machinery causes protein aggregation and proteotoxic stress. Nature 531, 191-195. doi: 10.1038/nature16973

Cohuet, A., Osta, M. A., Morlais, I., Awono-Ambene, P. H., Michel, K., Simard, F., et al. (2006). Anopheles and Plasmodium: from laboratory models to natural systems in the field. EMBO Rep. 7, 1285-1289.

Cornillot, E., Hadj-Kaddour, K., Dassouli, A., Noel, B., Ranwez, V., Vacherie, B., et al. (2012). Sequencing of the smallest Apicomplexan genome from the human pathogen Babesia microti. Nucleic Acids Res. 40, 9102-9114. doi: 10.1093/nar/ gks700

Cui, L., Lindner, S., and Miao, J. (2015). Translational regulation during stage transitions in malaria parasites. Ann. N. Y. Acad. Sci. 1342, 1-9. doi: 10.1111/ nyas. 12573

Dietel, A. K., Merker, H., Kaltenpoth, M., and Kost, C. (2019). Selective advantages favour high genomic AT-contents in intracellular elements. PLoS Genet. 15:e1007778. doi: 10.1371/journal.pgen.1007778

Dimitrova, L. N., Kuroha, K., Tatematsu, T., and Inada, T. (2009). Nascent peptidedependent translation arrest leads to Not4p-mediated protein degradation by the proteasome. J. Biol. Chem. 284, 10343-10352. doi: 10.1074/jbc.M808840200

Djuranovic, S. P., Erath, J., Andrews, R. J., Bayguinov, P. O., Chung, J. J., Chalker, D. L., et al. (2018). PolyA tracks and poly-lysine repeats are the achilles heel of Plasmodium falciparum. bioRxiv [Preprint]. doi: 10.1101/420109

Doma, M. K., and Parker, R. (2006). Endonucleolytic cleavage of eukaryotic mRNAs with stalls in translation elongation. Nature 440, 561-564. doi: 10.1038/ nature 04530

D’Orazio, K. N., Wu, C. C., Sinha, N., Loll-Krippleber, R., Brown, G. W., and Green, R. (2019). The endonuclease Cue 2 cleaves mRNAs at stalled ribosomes during No Go Decay. eLife 8:e49117. doi: 10.7554/eLife.49117

El Bissati, K., Zufferey, R., Witola, W. H., Carter, N. S., Ullman, B., and Ben Mamoun, C. (2006). The plasma membrane permease PfNT1 is essential for purine salvage in the human malaria parasite Plasmodium falciparum. Proc. Natl. Acad. Sci. U.S.A. 103, 9286-9291. doi: 10.1073/pnas.0602590103

Ellwood, M., and Nomura, M. (1982). Chromosomal locations of the genes for rRNA in Escherichia coli K-12. J. Bacteriol. 149, 458-468.

Fang, J., and McCutchan, T. F. (2002). Thermoregulation in a parasite's life cycle. Nature 418:742. doi: 10.1038/418742a

Florens, L., Washburn, M. P., Raine, J. D., Anthony, R. M., Grainger, M., Haynes, J. D., et al. (2002). A proteomic view of the Plasmodium falciparum life cycle. Nature 419, 520-526. doi: 10.1038/nature01107

Gardner, M. J., Hall, N., Fung, E., White, O., Berriman, M., Hyman, R. W., et al. (2002a). Genome sequence of the human malaria parasite Plasmodium falciparum. Nature 419, 498-511.

Gardner, M. J., Shallom, S. J., Carlton, J. M., Salzberg, S. L., Nene, V., Shoaibi, A., et al. (2002b). Sequence of Plasmodium falciparum chromosomes 2, 10, 11 and 14. Nature 419, 531-534.

Gardner, M. J., Tettelin, H., Carucci, D. J., Cummings, L. M., Aravind, L., Koonin, E. V., et al. (1998). Chromosome 2 sequence of the human malaria parasite Plasmodium falciparum. Science 282, 1126-1132. doi: 10.1126/science.282. 5391.1126

Garzia, A., Jafarnejad, S. M., Meyer, C., Chapat, C., Gogakos, T., Morozov, P., et al. (2017). The E3 ubiquitin ligase and RNA-binding protein ZNF598 orchestrates ribosome quality control of premature polyadenylated mRNAs. Nat. Commun. 8:16056. doi: $10.1038 /$ ncomms 16056

Ghorbal, M., Gorman, M., Macpherson, C. R., Martins, R. M., Scherf, A., and Lopez-Rubio, J. J. (2014). Genome editing in the human malaria parasite Plasmodium falciparum using the CRISPR-Cas9 system. Nat. Biotechnol. 32, 819-821. doi: 10.1038/nbt.2925

Giraldo-Calderon, G. I, Emrich, S. J., MacCallum, R. M., Maslen, G., Dialynas, E., Topalis, P., et al. (2015). VectorBase: an updated bioinformatics resource for invertebrate vectors and other organisms related with human diseases. Nucleic Acids Res. 43, D707-D713. doi: 10.1093/nar/gku1117

Glöckner, G. (2000). Large scale sequencing and analysis of AT rich eukaryote genomes. Curr. Genom. 1, 289-299. doi: 10.2174/1389202003351472

Guler, J. L., Freeman, D. L., Ahyong, V., Patrapuvich, R., White, J., Gujjar, R., et al. (2013). Asexual populations of the human malaria parasite, Plasmodium falciparum, use a two-step genomic strategy to acquire accurate, beneficial DNA amplifications. PLoS Pathog. 9:e1003375. doi: 10.1371/journal.ppat.1003375

Gunderson, J. H., Sogin, M. L., Wollett, G., Hollingdale, M., de la Cruz, V. F., Waters, A. P., et al. (1987). Structurally distinct, stage-specific ribosomes occur in Plasmodium. Science 238, 933-937. doi: 10.1126/science.367 2135

Guydosh, N. R., and Green, R. (2017). Translation of poly(A) tails leads to precise mRNA cleavage. RNA 23, 749-761. doi: 10.1261/rna.0604 18.116

Habich, M. (2016). PATACSDB - The database of polyA translational attenuators in coding sequences. PeerJ Comput. Sci. 2:e45. doi: 10.7717/peerj-cs.45

Hall, N., Pain, A., Berriman, M., Churcher, C., Harris, B., Harris, D., et al. (2002). Sequence of Plasmodium falciparum chromosomes 1, 3-9 and 13. Nature 419, 527-531.

Hamilton, W. L., Claessens, A., Otto, T. D., Kekre, M., Fairhurst, R. M., Rayner, J. C., et al. (2017). Extreme mutation bias and high AT content in Plasmodium falciparum. Nucleic Acids Res. 45, 1889-1901. doi: 10.1093/nar/gkw1259

Huckaby, A. C., Granum, C. S., Carey, M. A., Szlachta, K., Al-Barghouthi, B., Wang, Y. H., et al. (2019). Complex DNA structures trigger copy number variation across the Plasmodium falciparum genome. Nucleic Acids Res. 47, 1615-1627. doi: 10.1093/nar/gky1268

Hughes, K. R., Philip, N., Starnes, G. L., Taylor, S., and Waters, A. P. (2010). From cradle to grave: RNA biology in malaria parasites. Wiley Interdiscip. Rev. RNA 1, 287-303. doi: 10.1002/wrna.30

Hyman, R. W., Fung, E., Conway, A., Kurdi, O., Mao, J., Miranda, M., et al. (2002). Sequence of Plasmodium falciparum chromosome 12. Nature 419, 534-537.

Ito-Harashima, S., Kuroha, K., Tatematsu, T., and Inada, T. (2007). Translation of the poly(A) tail plays crucial roles in nonstop mRNA surveillance via translation repression and protein destabilization by proteasome in yeast. Genes Dev. 21, 519-524. doi: 10.1101/gad.1490207

Izawa, T., Tsuboi, T., Kuroha, K., Inada, T., Nishikawa, S., and Endo, T. (2012). Roles of dom34:hbs1 in nonstop protein clearance from translocators for normal organelle protein influx. Cell Rep. 2, 447-453. doi: 10.1016/j.celrep.2012. 08.010

Jamar, N. H., Kritsiligkou, P., and Grant, C. M. (2018). Loss of mRNA surveillance pathways results in widespread protein aggregation. Sci. Rep. 8:3894. doi: 10. 1038/s41598-018-22183-2

Juszkiewicz, S., and Hegde, R. S. (2017). Initiation of quality control during poly(A) translation requires site-specific ribosome Ubiquitination. Mol. Cell 65, 743-750.e4. doi: 10.1016/j.molcel.2016.11.039

Kanehisa, M., Sato, Y., Furumichi, M., Morishima, K., and Tanabe, M. (2019). New approach for understanding genome variations in KEGG. Nucleic Acids Res. 47, D590-D595. doi: 10.1093/nar/gky962

Kashima, I., Takahashi, M., Hashimoto, Y., Sakota, E., Nakamura, Y., and Inada, T. (2014). A functional involvement of ABCE1, eukaryotic ribosome recycling factor, in nonstop mRNA decay in drosophila Melanogaster cells. Biochimie 106, 10-16. doi: 10.1016/j.biochi.2014.08.001

Kim, H. K., Liu, F., Fei, J., Bustamante, C., Gonzalez, R. L., and Tinoco, I. (2014). A frameshifting stimulatory stem loop destabilizes the hybrid state and impedes ribosomal translocation. Proc. Natl. Acad. Sci. U.S.A. 111, 5538-5543. doi: 10. 1073/pnas.1403457111

Kobayashi, T. (2014). Ribosomal RNA gene repeats, their stability and cellular senescence. Proc. JPN Acad. Ser. B Phys. Biol. Sci. 90, 119-129. doi: 10.2183/ pjab. 90.119

Kooij, T. W., Janse, C. J., and Waters, A. P. (2006). Plasmodium post-genomics: better the bug you know? Nat. Rev. Microbiol. 4, 344-357. doi: 10.1038/ nrmicro1392

Koutmou, K. S., Schuller, A. P., Brunelle, J. L., Radhakrishnan, A., Djuranovic, S., and Green, R. (2015). Ribosomes slide on lysine-encoding homopolymeric a stretches. eLife 4:e05534. doi: 10.7554/eLife.05534

Kuroha, K., Akamatsu, M., Dimitrova, L., Ito, T., Kato, Y., Shirahige, K., et al. (2010). Receptor for activated C kinase 1 stimulates nascent polypeptidedependent translation arrest. EMBO Rep. 11, 956-961. doi: 10.1038/embor. 2010.169

Kurylo, C. M., Parks, M. M., Juette, M. F., Zinshteyn, B., Altman, R. B., Thibado, J. K., et al. (2018). Endogenous rRNA sequence variation can regulate stress response gene expression and phenotype. Cell Rep. 25, 236-248.e6. doi: 10.1016/ j.celrep.2018.08.093 
Lacsina, J. R., LaMonte, G., Nicchitta, C. V., and Chi, J. T. (2011). Polysome profiling of the malaria parasite Plasmodium falciparum. Mol. Biochem. Parasitol. 179, 42-46. doi: 10.1016/j.molbiopara.2011.05.003

Le Roch, K. G., Johnson, J. R., Florens, L., Zhou, Y., Santrosyan, A., Grainger, M., et al. (2004). Global analysis of transcript and protein levels across the Plasmodium falciparum life cycle. Genom. Res. 14, 2308-2318. doi: 10.1101/gr.2523904

Leiriao, P., Rodrigues, C. D., Albuquerque, S. S., and Mota, M. M. (2004). Survival of protozoan intracellular parasites in host cells. EMBO Rep. 5, 1142-1147. doi: 10.1038/sj.embor.7400299

Li, J., Gutell, R. R., Damberger, S. H., Wirtz, R. A., Kissinger, J. C., Rogers, M. J., et al. (1997). Regulation and trafficking of three distinct $18 \mathrm{~S}$ ribosomal RNAs during development of the malaria parasite. J. Mol. Biol. 269, 203-213. doi: 10.1006/jmbi.1997.1038

Liu, J., Istvan, E. S., Gluzman, I. Y., Gross, J., and Goldberg, D. E. (2006). Plasmodium falciparum ensures its amino acid supply with multiple acquisition pathways and redundant proteolytic enzyme systems. Proc. Natl. Acad. Sci. U.S.A. 103, 8840-8845. doi: 10.1073/pnas.060187 6103

Locati, M. D., Pagano, J. F. B., Girard, G., Ensink, W. A., van Olst, M., van Leeuwen, S., et al. (2017). Expression of distinct maternal and somatic 5.8S, $18 \mathrm{~S}$, and 28S rRNA types during zebrafish development. RNA 23, 1188-1199. doi: 10.1261/rna.061515.117

López-Barragán, M. J., Lemieux, J., Quiñones, M., Williamson, K. C., Molina-Cruz, A., Cui, K., et al. (2011). Directional gene expression and antisense transcripts in sexual and asexual stages of Plasmodium falciparum. BMC Genom. 12:587. doi: 10.1186/1471-2164-12-587

Loy, D. E., Plenderleith, L. J., Sundararaman, S. A., Liu, W., Gruszczyk, J., Chen, Y. J., et al. (2018). Evolutionary history of human. Proc. Natl. Acad. Sci. U.S.A. 115, E8450-E8459. doi: 10.1073/pnas.1810053115

Lu, J., and Deutsch, C. (2008). Electrostatics in the ribosomal tunnel modulate chain elongation rates. J. Mol. Biol. 384, 73-86. doi: 10.1016/j.jmb.2008. 08.089

Lu, X. M., Batugedara, G., Lee, M., Prudhomme, J., Bunnik, E. M., and Le Roch, K. G. (2017). Nascent RNA sequencing reveals mechanisms of gene regulation in the human malaria parasite Plasmodium falciparum. Nucleic Acids Res. 45, 7825-7840. doi: 10.1093/nar/gkx464

Majzoub, K., Hafirassou, M. L., Meignin, C., Goto, A., Marzi, S., Fedorova, A., et al. (2014). RACK1 controls IRES-mediated translation of viruses. Cell 159, 1086-1095. doi: 10.1016/j.cell.2014.10.041

Martin, L., Grigoryan, A., Wang, D., Wang, J., Breda, L., Rivella, S., et al. (2014). Identification and characterization of small molecules that inhibit nonsensemediated RNA decay and suppress nonsense p53 mutations. Cancer Res. 74, 3104-3113. doi: 10.1158/0008-5472.CAN-13-2235

Matsuda, R., Ikeuchi, K., Nomura, S., and Inada, T. (2014). Protein quality control systems associated with no-go and nonstop mRNA surveillance in yeast. Genes Cells 19, 1-12. doi: 10.1111/gtc.12106

McCutchan, T. F., de la Cruz, V. F., Lal, A. A., Gunderson, J. H., Elwood, H. J., and Sogin, M. L. (1988). Primary sequences of two small subunit ribosomal RNA genes from Plasmodium falciparum. Mol. Biochem. Parasitol. 28, 63-68. doi: 10.1016/0166-6851(88)90181-8

Mills, E. W., and Green, R. (2017). Ribosomopathies: there's strength in numbers. Science 358:eaan2755. doi: 10.1126/science.aan2755

Muralidharan, V., and Goldberg, D. E. (2013). Asparagine repeats in Plasmodium falciparum proteins: good for nothing? PLoS Pathog. 9:e1003488. doi: 10.1371/ journal.ppat.1003488

Muralidharan, V., Oksman, A., Iwamoto, M., Wandless, T. J., and Goldberg, D. E. (2011). Asparagine repeat function in a Plasmodium falciparum protein assessed via a regulatable fluorescent affinity tag. Proc. Natl. Acad. Sci. U.S.A. 108, 4411-4416. doi: 10.1073/pnas.1018449108

Muralidharan, V., Oksman, A., Pal, P., Lindquist, S., and Goldberg, D. E. (2012). Plasmodium falciparum heat shock protein 110 stabilizes the asparagine repeatrich parasite proteome during malarial fevers. Nat. Commun. 3:1310. doi: 10. 1038/ncomms 2306

Musto, H., Romero, H., Zavala, A., Jabbari, K., and Bernardi, G. (1999). Synonymous codon choices in the extremely GC-poor genome of Plasmodium falciparum: compositional constraints and translational selection. J. Mol. Evol. 49, 27-35. doi: 10.1007/p100006531
Ostera, G., Tokumasu, F., Teixeira, C., Collin, N., Sa, J., Hume, J., et al. (2011). Plasmodium falciparum: nitric oxide modulates heme speciation in isolated food vacuoles. Exp. Parasitol. 127, 1-8. doi: 10.1016/j.exppara.2010.05.006

Otto, T. D., Gilabert, A., Crellen, T., Böhme, U., Arnathau, C., Sanders, M., et al. (2018). Genomes of all known members of a Plasmodium subgenus reveal paths to virulent human malaria. Nat. Microbiol. 3, 687-697. doi: 10.1038/s41564018-0162-2

Pollack, Y., Katzen, A. L., Spira, D. T., and Golenser, J. (1982). The genome of Plasmodium falciparum. I: DNA base composition. Nucleic Acids Res. 10, 539-546. doi: 10.1093/nar/10.2.539

Qi, Y., Zhu, F., Eastman, R. T., Fu, Y., Zilversmit, M., Pattaradilokrat, S., et al. (2015). Regulation of Plasmodium yoelii oocyst development by strainand stage-specific small-subunit rRNA. mBio 6:e00117. doi: 10.1128/mBio.00 $117-15$

Quashie, N. B., Dorin-Semblat, D., Bray, P. G., Biagini, G. A., Doerig, C., RanfordCartwright, L. C., et al. (2008). A comprehensive model of purine uptake by the malaria parasite Plasmodium falciparum: identification of four purine transport activities in intraerythrocytic parasites. Biochem. J. 411, 287-295. doi: 10.1042/BJ20071460

Reddy, B. P., Shrestha, S., Hart, K. J., Liang, X., Kemirembe, K., Cui, L., et al. (2015). A bioinformatic survey of RNA-binding proteins in Plasmodium. BMC Genom. 16:890. doi: 10.1186/s12864-015-2092-1

Rogers, M. J., Gutell, R. R., Damberger, S. H., Li, J., McConkey, G. A., Waters, A. P., et al. (1996). Structural features of the large subunit rRNA expressed in Plasmodium falciparum sporozoites that distinguish it from the asexually expressed subunit rRNA. RNA 2, 134-145.

Saito, S., Hosoda, N., and Hoshino, S. (2013). The Hbs1-Dom34 protein complex functions in non-stop mRNA decay in mammalian cells. J. Biol. Chem. 288, 17832-17843. doi: 10.1074/jbc.M112.448977

Sakai, K., Ohta, T., Minoshima, S., Kudoh, J., Wang, Y., de Jong, P. J., et al. (1995). Human ribosomal RNA gene cluster: identification of the proximal end containing a novel tandem repeat sequence. Genomics 26, 521-526. doi: 10.1016/0888-7543(95)80170-q

Sengupta, J., Nilsson, J., Gursky, R., Spahn, C. M., Nissen, P., and Frank, J. (2004). Identification of the versatile scaffold protein RACK1 on the eukaryotic ribosome by cryo-EM. Nat. Struct. Mol. Biol. 11, 957-962. doi: 10.1038/ nsmb822

Seward, E. A., and Kelly, S. (2016). Dietary nitrogen alters codon bias and genome composition in parasitic microorganisms. Genom. Biol. 17:226.

Sherman, I. W. (1979). Biochemistry of Plasmodium (malarial parasites). Microbiol. Rev. 43, 453-495.

Shock, J. L., Fischer, K. F., and DeRisi, J. L. (2007). Whole-genome analysis of mRNA decay in Plasmodium falciparum reveals a global lengthening of mRNA half-life during the intra-erythrocytic development cycle. Genom. Biol. 8:R134.

Shoemaker, C. J., and Green, R. (2012). Translation drives mRNA quality control. Nat. Struct. Mol. Biol. 19, 594-601. doi: 10.1038/nsmb.2301

Silvestrini, F., Lasonder, E., Olivieri, A., Camarda, G., van Schaijk, B., Sanchez, M., et al. (2010). Protein export marks the early phase of gametocytogenesis of the human malaria parasite Plasmodium falciparum. Mol. Cell. Proteomics 9 , 1437-1448. doi: 10.1074/mcp.M900479-MCP200

Simms, C. L., and Zaher, H. S. (2016). Quality control of chemically damaged RNA. Cell Mol. Life Sci. 73, 3639-3653. doi: 10.1007/s00018-016-2261-7

Simms, C. L., Hudson, B. H., Mosior, J. W., Rangwala, A. S., and Zaher, H. S. (2014). An active role for the ribosome in determining the fate of oxidized mRNA. Cell Rep. 9, 1256-1264. doi: 10.1016/j.celrep.2014.10.042

Simms, C. L., Yan, L. L., and Zaher, H. S. (2017). Ribosome collision is critical for quality control during No-Go Decay. Mol. Cell 68, 361-373.e5. doi: 10.1016/j. molcel.2017.08.019

Sorber, K., Dimon, M. T., and DeRisi, J. L. (2011). RNA-Seq analysis of splicing in Plasmodium falciparum uncovers new splice junctions, alternative splicing and splicing of antisense transcripts. Nucleic Acids Res. 39, 3820-3835. doi: 10.1093/nar/gkq1223

Stevens, A. T., Howe, D. K., and Hunt, A. G. (2018). Characterization of mRNA polyadenylation in the apicomplexa. PLoS One 13:e0203317. doi: 10.1371/ journal.pone.0203317

Subtelny, A. O., Eichhorn, S. W., Chen, G. R., Sive, H., and Bartel, D. P. (2014). Poly(A)-tail profiling reveals an embryonic switch in translational control. Nature 508, 66-71. doi: 10.1038/nature13007 
Sueoka, N. (1962). On the genetic basis of variation and heterogeneity of DNA base composition. Proc. Natl. Acad. Sci. U.S.A. 48, 582-592. doi: 10.1073/pnas.48.4. 582

Sugiyama, T., Li, S., Kato, M., Ikeuchi, K., Ichimura, A., Matsuo, Y., et al. (2019). Sequential Ubiquitination of ribosomal protein uS3 triggers the degradation of non-functional 18S rRNA. Cell Rep. 26, 3400-3415.e7. doi: 10.1016/j.celrep. 2019.02.067

Sun, M., Li, W., Blomqvist, K., Das, S., Hashem, Y., Dvorin, J. D., et al. (2015). Dynamical features of the Plasmodium falciparum ribosome during translation. Nucleic Acids Res. 43, 10515-10524. doi: 10.1093/nar/gkv991

Sundaramoorthy, E., Leonard, M., Mak, R., Liao, J., Fulzele, A., and Bennett, E. J. (2017). ZNF598 and RACK1 regulate mammalian ribosome-associated quality control function by mediating regulatory $40 \mathrm{~S}$ ribosomal Ubiquitylation. Mol. Cell. 65, 751-760.e4. doi: 10.1016/j.molcel.2016.12.026

Szafranski, K., Lehmann, R., Parra, G., Guigo, R., and Glöckner, G. (2005). Gene organization features in A/T-rich organisms. J. Mol. Evol. 60, 90-98. doi: 10.1007/s00239-004-0201-2

Tang, T. T. L., Stowell, J. A. W., Hill, C. H., and Passmore, L. A. (2019). The intrinsic structure of poly(A) RNA determines the specificity of Pan2 and Caf1 deadenylases. Nat. Struct. Mol. Biol. 26, 433-442. doi: 10.1038/s41594-0190227-9

Tesina, P., Lessen, L. N., Buschauer, R., Cheng, J., Wu, C., Berninghausen, O., et al. (2019). Molecular mechanism of translational stalling by inhibitory codon combinations and poly(A) tracts. bioRxiv [Preprint]. doi: 10.1101/755652

Thurmond, J., Goodman, J. L., Strelets, V. B., Attrill, H., Gramates, L. S., Marygold, S. J., et al. (2019). FlyBase 2.0: the next generation. Nucleic Acids Res. 47, D759-D765. doi: 10.1093/nar/gky1003

Ting, L. M., Shi, W., Lewandowicz, A., Singh, V., Mwakingwe, A., Birck, M. R., et al. (2005). Targeting a novel Plasmodium falciparum purine recycling pathway with specific immucillins. J. Biol. Chem. 280, 9547-9554. doi: 10.1074/jbc. $\mathrm{m} 412693200$

Tournu, H., Butts, A., and Palmer, G. E. (2019). Titrating gene function in the human fungal pathogen Candida albicans through Poly-adenosine tract insertion. mSphere 4, e192-e119. doi: 10.1128/mSphere.00192-19

Tsuboi, T., Kuroha, K., Kudo, K., Makino, S., Inoue, E., Kashima, I., et al. (2012). Dom34:hbs1 plays a general role in quality-control systems by dissociation of a stalled ribosome at the $3^{\prime}$ end of aberrant mRNA. Mol. Cell. 46, 518-529. doi: 10.1016/j.molcel.2012.03.013

van Spaendonk, R. M., Ramesar, J., van Wigcheren, A., Eling, W., Beetsma, A. L., van Gemert, J., et al. (2001). Functional equivalence of structurally distinct ribosomes in the malaria parasite, Plasmodium berghei. J. Biol. Chem. 276, 22638-22647. doi: 10.1074/jbc.m101234200

Velichutina, I. V., Rogers, M. J., McCutchan, T. F., and Liebman, S. W. (1998). Chimeric rRNAs containing the GTPase centers of the developmentally regulated ribosomal rRNAs of Plasmodium falciparum are functionally distinct. RNA 4, 594-602. doi: 10.1017/s1355838298980049

Vembar, S. S., Droll, D., and Scherf, A. (2016a). Translational regulation in blood stages of the malaria parasite Plasmodium spp.: systems-wide studies pave the way. Wiley Interdiscip. Rev. RNA 7, 772-792. doi: 10.1002/wrna.1365

Vembar, S. S., Seetin, M., Lambert, C., Nattestad, M., Schatz, M. C., Baybayan, P., et al. (2016b). Complete telomere-to-telomere de novo assembly of the Plasmodium falciparum genome through long-read (>11 kb), single molecule, real-time sequencing. DNA Res. 23, 339-351. doi: 10.1093/dnares/ dsw022

Videvall, E. (2018). Plasmodium parasites of birds have the most AT-rich genes of eukaryotes. Microb. Genom. 4:e000150. doi: 10.1099/mgen.0.000150

Walliker, D., Quakyi, I. A., Wellems, T. E., McCutchan, T. F., Szarfman, A., London, W. T., et al. (1987). Genetic analysis of the human malaria parasite Plasmodium falciparum. Science 236, 1661-1666. doi: 10.1126/science. 3299700
Warner, J. R. (1999). The economics of ribosome biosynthesis in yeast. Trends Biochem. Sci. 24, 437-440. doi: 10.1016/s0968-0004(99)01460-7

Waters, A. P., Syin, C., and McCutchan, T. F. (1989). Developmental regulation of stage-specific ribosome populations in Plasmodium. Nature 342, 438-440. doi: $10.1038 / 342438 \mathrm{a} 0$

Wernegreen, J. J., and Funk, D. J. (2004). Mutation exposed: a neutral explanation for extreme base composition of an endosymbiont genome. J. Mol. Evol. 59, 849-858. doi: 10.1007/s00239-003-0192-z

Winegard, T. C. (2019). The Mosquito: A Human History of Our Deadliest Predator. Melbourne: Text Publishing Company.

Wolf, A. S., and Grayhack, E. J. (2015). Asc1, homolog of human RACK1, prevents frameshifting in yeast by ribosomes stalled at CGA codon repeats. RNA 21, 935-945. doi: 10.1261/rna.049080.114

Wong, W., Bai, X. C., Brown, A., Fernandez, I. S., Hanssen, E., Condron, M., et al. (2014). Cryo-EM structure of the Plasmodium falciparum $80 \mathrm{~S}$ ribosome bound to the anti-protozoan drug emetine. eLife 3:e03080. doi: 10.7554/eLife. 03080

World Health Organization [WHO], (2018). World Malaria Report 2018. Geneva: World Health Organization.

Wu, H., Zhang, Z., Hu, S., and Yu, J. (2012). On the molecular mechanism of GC content variation among eubacterial genomes. Biol. Direct 7:2. doi: 10.1186/ 1745-6150-7-2

Xue, S., and Barna, M. (2012). Specialized ribosomes: a new frontier in gene regulation and organismal biology. Nat. Rev. Mol. Cell Biol. 13, 355-369. doi: $10.1038 / \mathrm{nrm} 3359$

Yeoh, L. M., Goodman, C. D., Mollard, V., McHugh, E., Lee, V. V., Sturm, A., et al. (2019). Alternative splicing is required for stage differentiation in malaria parasites. Genom. Biol. 20:151. doi: 10.1186/s13059-0191756-6

Yonashiro, R., Tahara, E. B., Bengtson, M. H., Khokhrina, M., Lorenz, H., Chen, K. C., et al. (2016). The Rqc2/Tae2 subunit of the ribosome-associated quality control (RQC) complex marks ribosome-stalled nascent polypeptide chains for aggregation. eLife 5:e11794. doi: 10.7554/eLife.11794

Zanghì, G., Vembar, S. S., Baumgarten, S., Ding, S., Guizetti, J., Bryant, J. M., et al. (2018). A specific PfEMP1 is expressed in falciparum, $P$., sporozoites and plays a role in hepatocyte infection. Cell Rep. 22, 2951-2963. doi: 10.1016/j.celrep.2018. 02.075

Zhang, M., Wang, C., Otto, T. D., Oberstaller, J., Liao, X., Adapa, S. R., et al. (2018). Uncovering the essential genes of the human malaria parasite. Science 360:eaa7847. doi: 10.1126/science.aap7847

Zhu, J. D., Waters, A. P., Appiah, A., McCutchan, T. F., Lal, A. A., and Hollingdale, M. R. (1990). Stage-specific ribosomal RNA expression switches during sporozoite invasion of hepatocytes. J. Biol. Chem. 265, 12740-12744.

Zilversmit, M. M., Volkman, S. K., DePristo, M. A., Wirth, D. F., Awadalla, P., and Hartl, D. L. (2010). Low-complexity regions in Plasmodium falciparum: missing links in the evolution of an extreme genome. Mol. Biol. Evol. 27, 2198-2209. doi: $10.1093 / \mathrm{molbev} / \mathrm{msq} 108$

Conflict of Interest: The authors declare that the research was conducted in the absence of any commercial or financial relationships that could be construed as a potential conflict of interest.

Copyright (C) 2019 Erath, Djuranovic and Djuranovic. This is an open-access article distributed under the terms of the Creative Commons Attribution License (CC BY). The use, distribution or reproduction in other forums is permitted, provided the original author(s) and the copyright owner(s) are credited and that the original publication in this journal is cited, in accordance with accepted academic practice. No use, distribution or reproduction is permitted which does not comply with these terms. 